\title{
Adaptive photovoltaic solar module based on internet of things and web-based monitoring system
}

\author{
Murizah Kassim, Fadila Lazim \\ School of Electrical Engineering, College of Engineering, Universiti Teknologi MARA, Shah Alam, Selangor, Malaysia
}

\begin{tabular}{l}
\hline \hline Article Info \\
\hline Article history: \\
Received Mar 28, 2021 \\
Revised Jul 21, 2021 \\
Accepted Aug 12, 2021 \\
\hline
\end{tabular}

Keywords:

Adaptive solar photovoltaic

Internet of things

Monitoring system

Real-time

Solar tracker

Web-based

\begin{abstract}
This paper presents an intelligent of single axis automatic adaptive photovoltaic solar module. A static solar panel has an issue of efficiency on shading effects, irradiance of sunlight absorbed, and less power generates. This aims to design an effective algorithm tracking system and a prototype automatic adaptive solar photovoltaic (PV) module connected through internet of things (IoT). The system has successfully designated on solving efficiency optimization. A tracking system by using active method orientation and allows more power and energy are captured. The solar rotation angle facing aligned to the light-dependent resistor (LDR) voltage captured and high solar panel voltage measured by using Arduino microcontroller. Real-time data is collected from the dynamic solar panel, published on Node-Red webpage, and running interactive via android device. The system has significantly reduced time. Data captured by the solar panel then analyzed based on irradiance, voltage, current, power generated and efficiency. Successful results present a live data analytic platform with active tracking system that achieved larger power generated and efficiency of solar panel compared to a fixed mounted array. This research is significant that can help the user to monitor parameters collected by the solar panel thus able to increase $51.82 \%$ efficiency of the PV module.
\end{abstract}

This is an open access article under the CC BY-SA license.

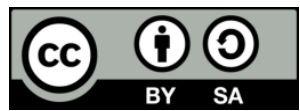

\section{Corresponding Author:}

Murizah Kassim

School of Electrical Engineering, College of Engineering, Universiti Teknologi MARA

40450 UiTM Shah Alam, Selangor, Malaysia

Email: murizah@uitm.edu.my

\section{INTRODUCTION}

Many previous researchers have been done to extend the photovoltaic solar module to support energies. Some research has been on the performance of grid-tied photovoltaic solar systems [1], behavior search algorithm on estimation of solar photovoltaic [2] and design for cost reduction and system compliance for Photovoltaic solar farm [3]. Renewable energy is the alternative power source in achieving greater popularity and solar photovoltaic is a good combination that can offer beneficial solutions [4]. The research mentioned that solar energy is consistent for life-long potential energy supply. The sustainable energy development authority of Malaysia (SEDA) is a statutory body adopted the feed-in tariff (FIT) mechanism which allows renewable energy producers to sell electricity to utility companies [5]. Malaysia has a tropical climate which are quite high temperatures, high humidity and naturally has good solar radiation since located nearly equator which has a great potential to develop solar energy [6]. The existing method using chronological and passive are the common practices for a solar installation is the kind of operation need a lot of power consumption to activate the motor movement base on a timer and having complexity working principles [7]. This research identifies the suitable parameter used on a tracking system to reduce motor movement power usage and reduce system complexity so that can enhance energy captures. In addition, 
typical practical assessments by the student are observations and measurements made at the site where the static position solar panel is located. Therefore, the trainer needs to supervise closely and difficult to collect data physically which is placed quite far outside from building. This situation has led to difficulty in data acquisition. The other issue rises in the existing photovoltaic solar module is that the fixed position system is not efficient [8]. Solar panels which are fixed angle mounted facing to the sky can reduce the amount of energy captured by the cell. As a result, only a certain amount of output power generates by the solar cells. Therefore, irradiation of sunlight to the solar panel is highly reduced, resulting in sufficiently less power generates by the solar module [9].

The aim of this research is to develop a solar tracking device prototype that can be absorbed solar energy and operates at their greatest efficiency, establish design requirements for a tracking device by identifying a key feature required by the solar panel and propose a solution by using technology of IoT system to access the data from sensors mounted on adaptive photovoltaic module so that can be retrieved in real-time from web page developed and Android apps. Creating mobile apps is an opportunity as new Industry revolutions, IR 4.0 focus today where the system can be mobility, online and real-time tracking system. This prototype developed solar panel with sensor-equipped to detect the light presence and sensing mode to track the higher solar panel voltage. The controller Arduino Uno used to operate the tracking system. The system developed by combining with IoT devices using Raspberry Pi 3 to build up a wireless connection between machine to machine for the purpose of data collection, monitoring, control or maintenance of various aspects [10]. This prototype is also suitable as an educator training kit with embedded intelligence for faster data acquisition at any remote location. Real-time is data obtained from an adaptive solar photovoltaic module send to the network and easy to monitor by a webpage dashboard and Android devices. The data can be tabulated and present in various formats, such as responsive tables, graphs, and charts so that performance analysis can be done. This research has successfully developed a MySolar prototype and significant that can help to monitor power generated by the solar PV module thus able to control possible results in future implementations.

\section{MATERIALS AND METHODS}

\subsection{Materials}

Three basic working principles were chosen to understand more about the system operation and development that brings the ideas on the prototype development with a suitable tracking system parameter and increase efficiency.

\subsubsection{Internet of things system}

Internet of things (IoT) refers to a concept that involves the connection of various things or objects through a wired or wireless connection of interaction and creation of an application to fulfill a particular task. IoT which has emerged and today it is being considered where some IoT-based electricity energy monitoring system has been developed [11]. IoT technology has continuously connected to the digital world to control, monitoring, maintenance, and data reception depending on the function needed. Many research questions are queries to develop of an IoT embedded solar tracker which have a connection between Machine to machine (M2M) and create feasible real-time data monitoring. The implementation can be done by using the microcontroller as a control unit. This research is a combination of software and hardware components which communicate together to run the system. There is a large volume of published studies describing the role of applying wireless network and telecommunication technology such as Wi-Fi to IoT network system is popular for high-speed internet connectivity with a smartphone or other device that has Wi-Fi module [12]. The content that the Wi-Fi enabled to send the sensor status or data to the server [13]. However, recent studies have suggested that to consider parameters like type of communication, cost, technology and efficiency of the system when choosing with different technologies like Wi-Fi, Bluetooth, European Commission of global system for mobile communications internet of things (EC-GSM-IoT), radio frequency identifier (RFID) and Near-field communication (NFC) [14]. Raspberry Pi 3 is capable that built in with Wi-Fi and Bluetooth to help it connect with several networks. The data collected by sensors is interfacing to the microcontroller. This research is used microcontroller unit (MCU) embedded system hardware. A microcontroller is basically referring to a central processing unit (CPU). Microcontrollers provide pin access which allows monitoring sensors, set motor, and transfer data to another device. There are many types of MCU such as Arduino, NodeMCu and Raspberry Pi. The higher performance comparison between Raspberry $\mathrm{Pi}$, Arduino, and NodeMCu, in terms of its storage and computing, speeds the raspberry is better. Raspberry $\mathrm{Pi}$ and NodeMCu have a Wi-Fi connection to the internet, but Raspberry Pi has a more advanced feature with Bluetooth connection [15]. The boards like Arduino need another Wi-Fi shield to make it connect to the internet. In term of specification and performance analysis, Raspberry Pi emerges as a winner when it comes 
to satisfying most of the functional requirements of IoT systems and able to integrate with IoT which capitalizes on the massive non-expert community that has grown around the Pi concept [16].

\subsubsection{Relevant technologies}

The primary question is why the necessity of a new design of solar module needed in this research. Many studies have been done by the researcher to achieve the maximum power output and efficiency of the solar module so that can maintain the tracking system able to follow the maximum range of voltage with a certain degree of accuracy [17], [18]. Nowadays, most photovoltaic modules (PV) are placed in a static position. The array has an immovable orientation to the sky and does not turn to follow the sun. Light gathering is dependent on the angle of incidence of the light source providing power like the sun to the solar cell's surface, and the closer to perpendicular, the greater the power captured [19]. Commonly, it placed fix to the roof or mounted directly onto a frame structure on the ground. However, throughout the day, the sun is moving from east to west and constantly changing its position making the inappropriate energy captured. Therefore, the solar module needs some enhancement in structure development so that can improve the efficiencies. Other technologies involved web-based monitoring system [20], real-time data collections, enhanced in latest transmission communications and mobile applications [21].

\subsubsection{Related works}

A few research about solar PV modules working principles has presented that the better absorbing surface of the solar module can be orientated to the position of the sun by using two angles, azimuth and zenith [22]. There are two types of solar tracking orientation which is single and double axis orientation. The single axis tracking system is the simplest solution and the most recommended solution to apply in the tropical region. In Malaysia, the sunbeam is always directed to land and solar radiance does not vary by seasons. Malaysia does not have four seasons and is located at the equator; therefore, it is suitable to use the single axis tracking system instead of a dual-axis tracking system [23]. There are many drawbacks of dualaxis sun tracking system in the previous system where the sensor unsuccessfully tracks the sun accurately during the low solar irradiance level condition [24]. Another research has found that dual axis does a better job of keeping the sunbeam perpendicular to the solar cell. However, these systems can be complex and expensive [25]. The using single-axis position can minimize the energy consumption of the motor movement so that more energy can be saved for other applications usage as shown in Figure 1.

There are three methods of tracking: active, passive and chronological tracking [26]. The lightdependent resistor (LDR) sensor has been used and continuously searching the sunbeam in active tracking method. PV module will always face the sun the sensors trigger the motor to rotate the panel in the right position. A chronological tracker is a programming setup tracking system whereby the cell structure is moved at a certain angle throughout the day. Thus, the motor or actuator is programmed to continuously rotate at a certain angle per hour. The continuous rotation of the motor or actuator means more power consumption and tracking the sun on a very cloudy day is unnecessary [27]. Passive tracking is same as active tracking with a combination of programming chronological type however these systems typically require costly and complex tracking devices [28]. The active solar tracker has been chosen in this paper with the key features identified in this research to solve the complexity programming script by the chronological and passive method and minimum usage power in motor movement. Based on the reviewed papers gap analysis has been done and improvement of cell types, types of installation, panel orientation, method of tracking and IoT website have been developed in this research.

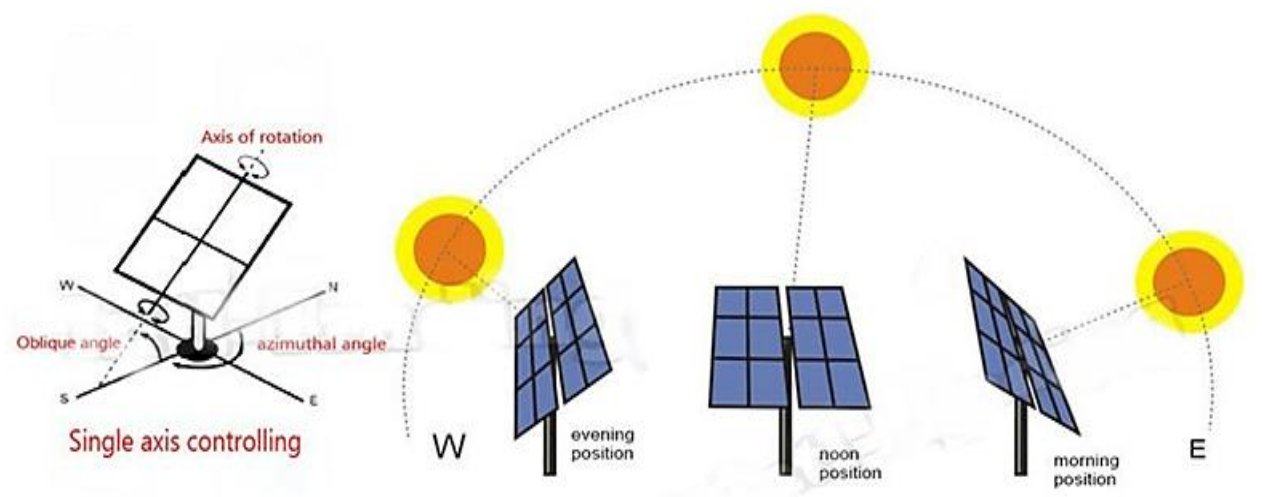

Figure 1. Single axis control system 


\subsection{Method}

\subsubsection{System flowchart}

Figure 2 shows a system flowchart from the panel movement algorithm setup, parameters setup, data collections and process of design webpage and android. Data collected by manually using multimeter and pyrometer in a day as a reference to sketch the program using Arduino integrated development environment (IDE). Begin with solar panel performance analysis studies where data is collected in every 1-hour time intervals in a day the system tracking, and monitoring can be done.

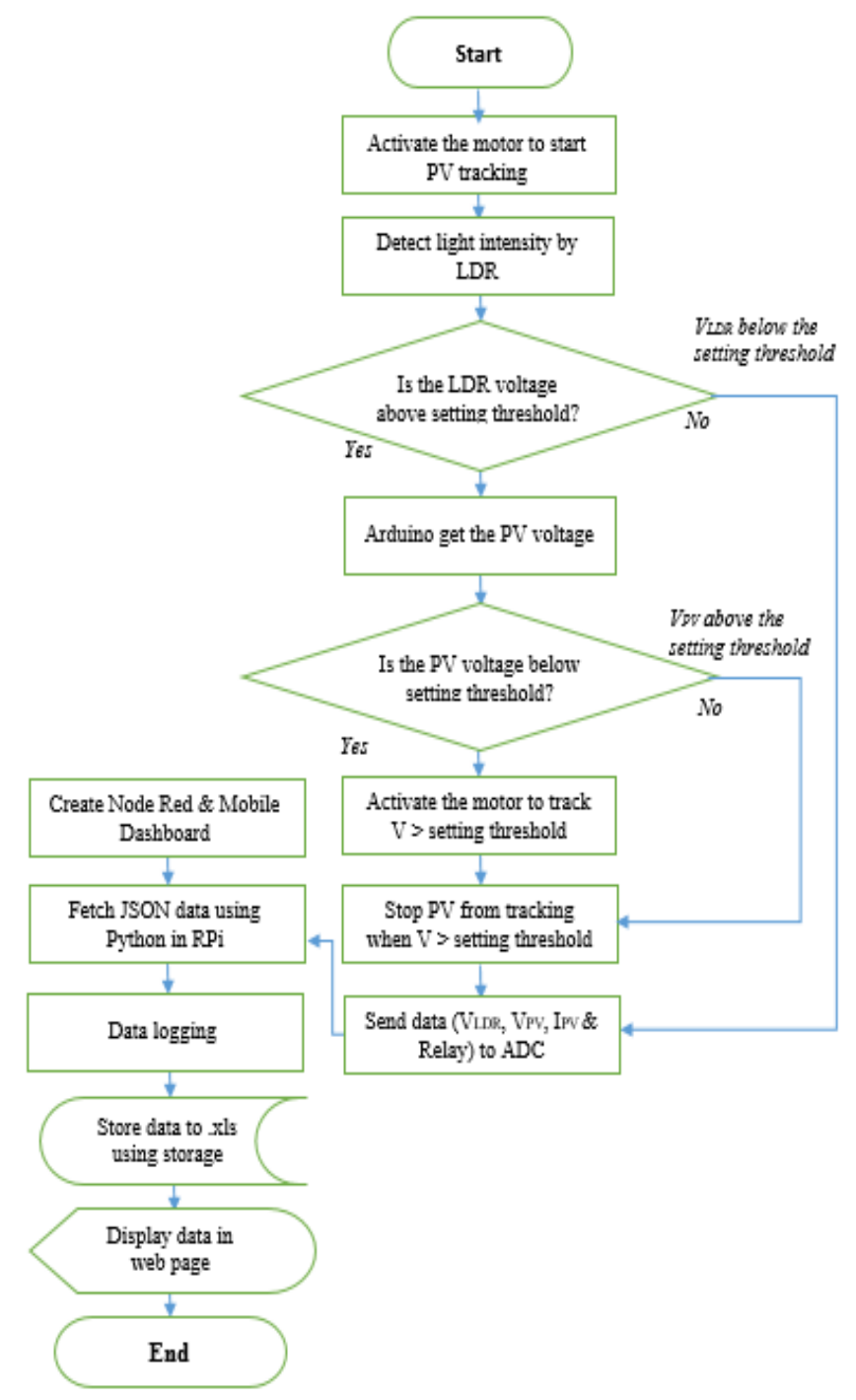

Figure 2. System flowchart

Figure 3 shows the data by manually collected using 5 Watt solar panel to investigate interrelation between irradiance, current, voltage, and efficiency of the solar panel. The solar panel was placed on a horizontal surface about $30-100 \mathrm{~cm}$ high facing the sun at static position. Data taken during daytime from 8 am to $5 \mathrm{pm}$ at Shah Alam. The relationship between irradiance, current, voltage and efficiency are the key point approaches in developing this prototype movement algorithm. This electrical characteristic helped to identify a suitable parameter to optimize the solar panel efficiency. The formula of $V_{o c}$ shows the interrelation of these parameter $V_{o c}$ and $I_{s c}$ where the $V_{o c}$ is proportional to $I_{s c}$ as given in (1) [29].

$$
V_{o c}=\frac{k T}{q} \operatorname{In}\left(\frac{I s c}{I o}+1\right)
$$

The formula of efficiency as given in (2) [30]: 
Efficiency $=\frac{\text { Power }(\text { Watt })}{\text { Area } \times \text { Pin }}=\frac{\text { Voc } \times \text { Isc }}{\text { Area } \times \text { Pin }}$

where Pin $=$ Incident power $=1000 \mathrm{Wm}^{-2}$ at STC

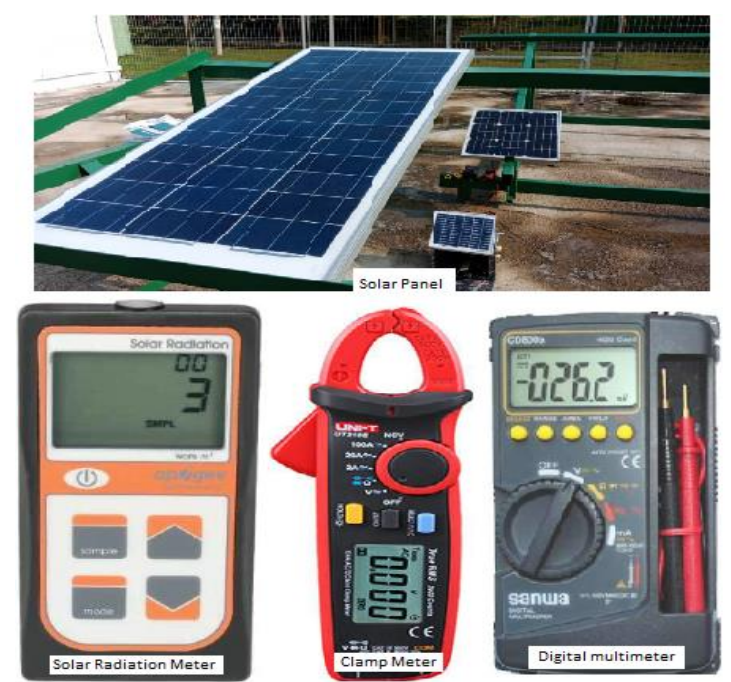

Figure 3. Data collection with solar

\subsubsection{Tracking system development}

The whole system is mainly divided into two stages, one is tracking system, and another is a monitoring system. This research used single axis solar tracker follow east to west movement. The tracker model consisted of a solar panel, solar charge controller, battery, direct current (DC) motor, motor driver and Arduino Uno R3. The solar charge controller attached to the solar array in hardware development. This solar charge controller manages the power from the array into the battery bank to ensure that the batteries are not overcharged, and the power does not run back to the solar panel overnight. Solar panels help to store the energy in the battery. The Arduino is used to control the LDR sensor and solar voltage to track the panel turn up-down movement based on the data given to microcontroller. DC motor connected to a motor driver board. The solar tracking mechanism is driven by this DC geared motor. The motor can simply be controlled with the on-board switches and speed potentiometer by using motor driver circuit board. Solar panel up-down movement based on the limit switch upper and lower installed at the box casing. These geared motor and sensors are interfaced together with a microcontroller. The overall hardware specification used as illustrated in Table 1.

Table 1. Hardware specification

\begin{tabular}{cc}
\hline Hardware & Specification \\
\hline Motor & Solar panel of Polycrystalline (5 Watt) \\
& Worm gear DC Motor \\
Motor driver board & Speed: 260 rpm Torque: 9 kg.cm \\
Microcontroller/Processor & Cytron MD30C, Vin 5-25 Vdc, \\
Arrent sensor & Arduino Uno ATMEGA328P \\
ADC & Raspberry Pi3 B+ \\
Solar charger controller & ACS712 \\
Battery & MCP 3208 \\
& $12-24$ V VC, 10 A \\
\hline
\end{tabular}

Two main parts to communicate client to server and published message to webpage platform are ADC IC MCP3208 and Raspberry Pi3. Since RPi does not have a built-in analog to digital converter, the external component must be used as a converter. MCP3208 acts as an external component associate with RPi by open analog signal to RPi programs. The python library designed to published data and read up to 8 pin channels. The entire schematic as illustrated in Figure 4. 


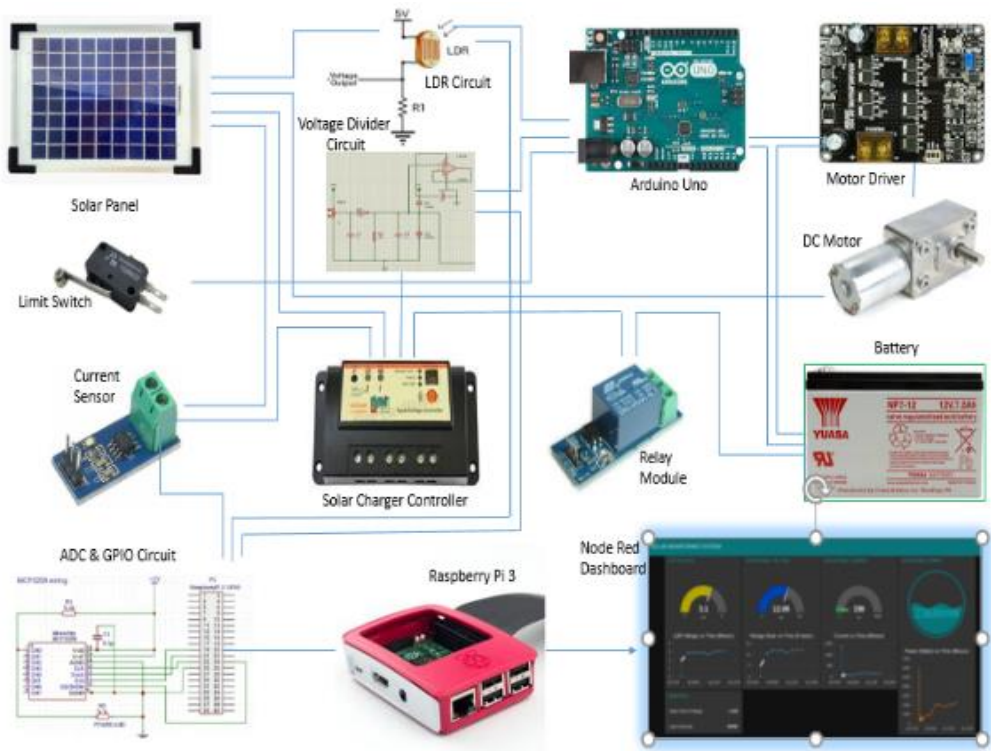

Figure 4. The entire schematic

\subsubsection{Monitoring development}

The software design implementation of this system can be divided into two main parts, transmitter, and receiver. At the transmitter side, the sensors collect all the data needed. The message queuing telemetry transport (MQTT) used to publish data using MQTT and forward data to the subscriber. The Wi-Fi module on RPi starts to communicate to the internet by using Python script. Node-Red is used as a flow deployment platform to wire together hardware devices using graphical nodes and flow-based method. The Node-Red created a web page for IoT at the receiving end. The Wi-Fi broadcast the data to web server indicates by Node-Red webpage dashboard and android. Data logging can be store into Node-Red context storage in excel format. Data then is analyzed where parameter input such as voltage, current, and power is displayed in graph and gauge meter in laptop or pc monitor. In addition, data also can be displayed on a mobile phone where realtime data for monitoring purpose from any remote location. Figure 5 shows the system architecture for the prototype development system.

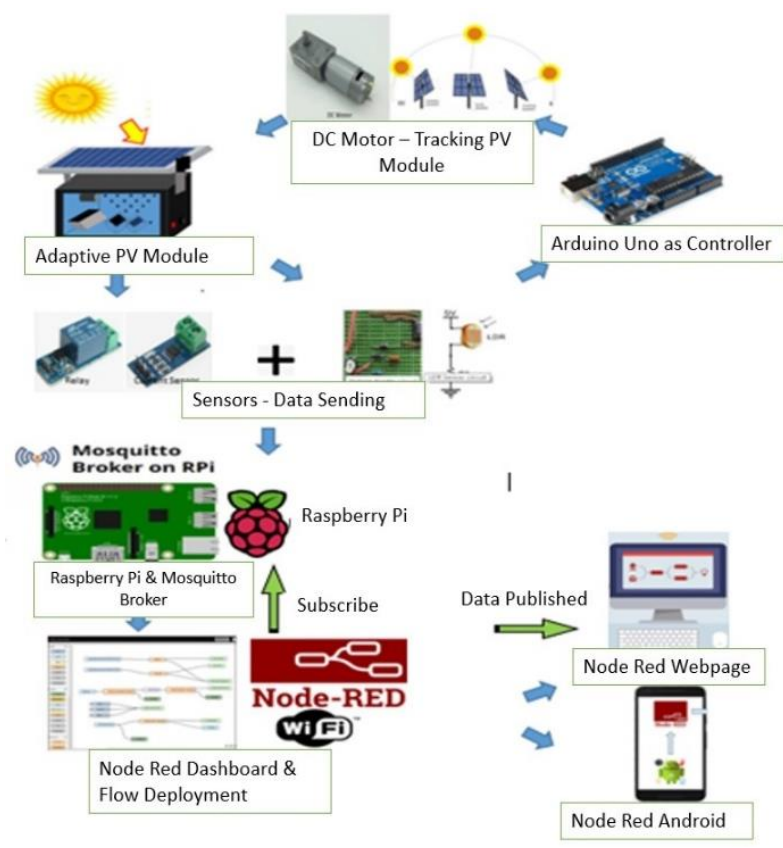

Figure 5. The system architecture 


\section{RESULT AND DISCUSSION}

Table 2 shows the data by manually collected using this solar panel to examine interrelation between irradiance, current, voltage, power, and efficiency of the solar panel. This prototype established design requirements by identifying key features required by the solar panel to produce an intelligent algorithm tracking system. Figure 6 shows the electrical characteristic of solar panel $V_{o c}$ and $I_{s c}$ was proportional to irradiance. The higher voltage and current indicates the better solar irradiance collected by the panel. This means that when solar irradiance increase, the output voltage and current also increases.

Figure 7 shows the voltage, $V_{\text {oc }}$ and current, $I_{\text {sc }}$ measured on daytime from 8:00 to 5:00 pm. The result presents that voltages, $\mathrm{V}_{\mathrm{oc}}$ data tabulated higher than current, $\mathrm{I}_{\mathrm{sc}}$. The $\mathrm{I}_{\mathrm{sc}}$ values collected had a small range from 0-600 mA. This parameter was difficult to measure and monitor the tracking system sensor data. The most suitable parameter used is voltage, $\mathrm{V}_{\text {oc }}$. Moreover, the higher ranges of $\mathrm{V}_{\text {oc }}$ gives more advantage to the sensing system and high accuracy so that the tracking system can perform well in searching for the appropriate solar irradiance.

Table 2. Solar panel $5 \mathrm{~W}$ harvested per day

\begin{tabular}{cccccc}
\hline Time (hours) & Irradiance $(\mathrm{w} / \mathrm{m} 2)$ & Current (amps) & Voltage (volts) & Power (watts) & Efficiency $(\%)$ \\
\hline $8: 00$ & 302 & 0.04 & 6.98 & 0.34 & 1.48 \\
$9: 00$ & 344 & 0.16 & 9.57 & 1.63 & 7.09 \\
$10: 00$ & 436 & 0.36 & 11.22 & 4.04 & 17.56 \\
$11: 00$ & 618 & 0.38 & 12.36 & 4.70 & 20.42 \\
$12: 00$ & 720 & 0.42 & 12.7 & 5.33 & 23.19 \\
$13: 00$ & 790 & 0.54 & 12.8 & 6.91 & 30.05 \\
$14: 00$ & 780 & 0.49 & 12.69 & 6.22 & 27.04 \\
$15: 00$ & 640 & 0.34 & 12.16 & 4.13 & 17.98 \\
$16: 00$ & 520 & 0.26 & 10.26 & 2.91 & 12.66 \\
$17: 00$ & 308 & 0.06 & 7.45 & 0.63 & 2.73 \\
& & & AVE: & 3.68 & 16.02 \\
\hline
\end{tabular}
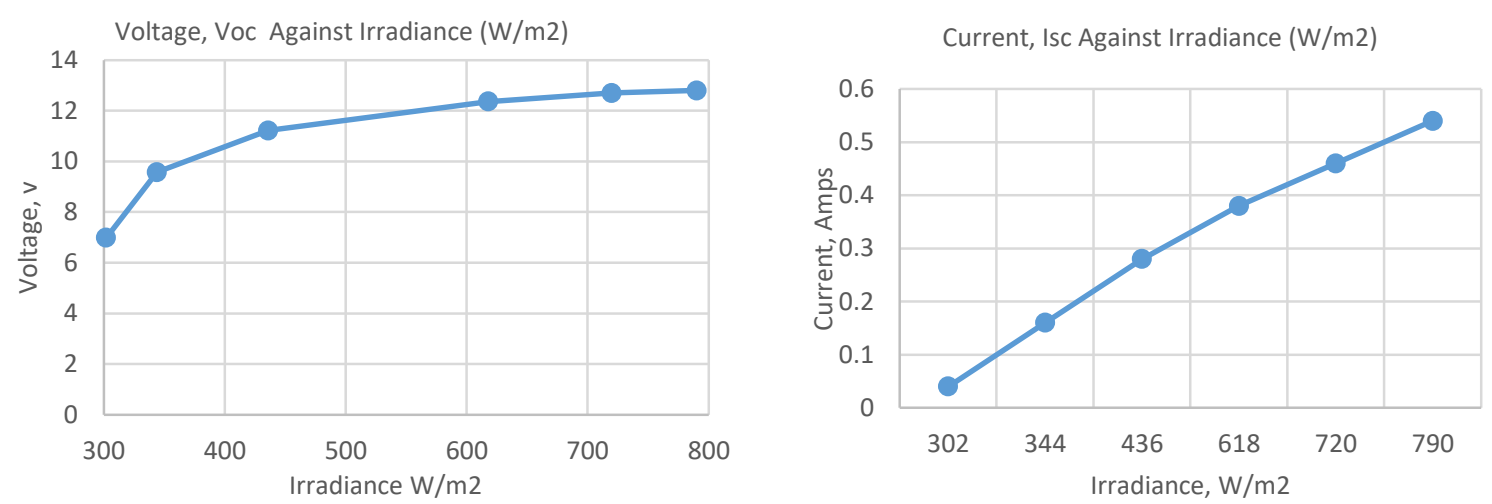

Figure 6. Output current and voltage against irradiance

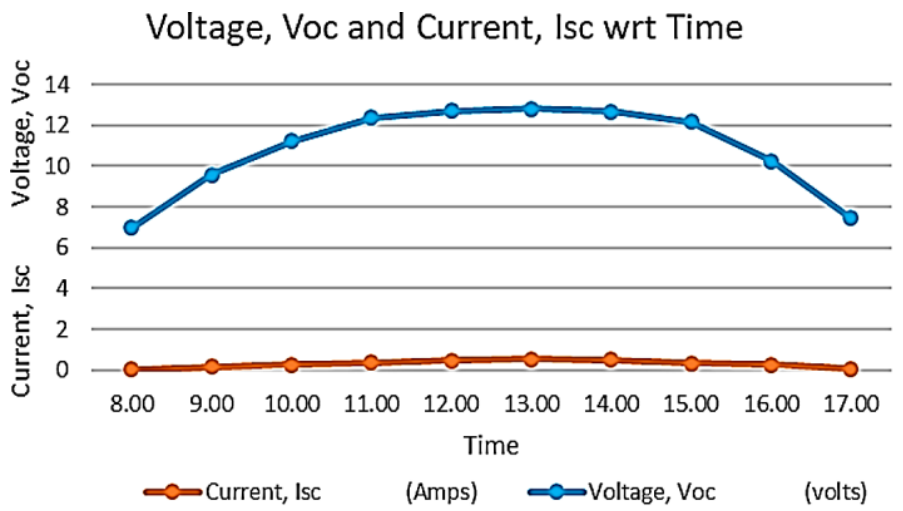

Figure 7. Comparison $\mathrm{V}_{\mathrm{oc}}$ and $\mathrm{I}_{\mathrm{sc}}$ during daytime 
Table 3 shows the LDR voltage affected by irradiance when experimented on 6:30 to 8:15 am and 6:00 to 8:00 pm. When irradiance increase, the LDR voltage also increases. It shows that the LDR voltage parameter suitable to use in the tracking method to start up the system during early morning and close system during the late evening. The hybrid working principle associated with voltage, $\mathrm{V}_{\mathrm{oc}}$ can produce an effective tracking system.

\begin{tabular}{ccccc}
\multicolumn{6}{c}{ Table 3. LDR data collected during day/night } \\
\hline $\begin{array}{c}\text { Time } \\
(\mathrm{am})\end{array}$ & $\begin{array}{c}\text { Irradiance } \\
\left(\mathrm{w} / \mathrm{m}^{2}\right)\end{array}$ & $\begin{array}{c}\text { Current } \\
(\mathrm{mA})\end{array}$ & $\begin{array}{c}\text { Voltage } \\
(\text { Volts })\end{array}$ & $\begin{array}{c}\text { VLDR } \\
(\text { Volts })\end{array}$ \\
\hline $6: 30$ & 0 & - & - & 0.09 \\
$6: 45$ & 0 & - & - & 0.84 \\
$7: 00$ & 1 & - & - & 1.03 \\
$7: 15$ & 14 & - & - & 1.65 \\
$7: 30$ & 41 & - & - & 1.55 \\
$7: 45$ & 45 & 2.84 & 0.16 & 1.75 \\
$8: 00$ & 64 & 2.92 & 0.18 & 2.10 \\
$8: 15$ & 69 & 2.99 & 0.34 & 2.85 \\
$18: 00$ & 540 & 2.08 & 0.52 & 2.22 \\
$18: 30$ & 201 & 2.22 & 0.43 & 1.43 \\
$19: 00$ & 18 & 1.02 & 0.1 & 1.1 \\
\hline
\end{tabular}

Figures 8 and 9 show the solar monitoring system that Relay module, LDR sensor, a current sensor, and solar voltage published all the data and send it to Raspberry Pi 3 using Node-Red platform. IoT platforms prove itself very helpful to communicates between machines to a machine. The information is visible via Node-Red platform and Android, making an interpretation into our required way. It communicates in a distributed network to ensure the user can obtain real-time data logging at any remote location. The webbased interface will significantly reduce the time of manually data collection. Hence, this prototypes system is flexible and user-friendly which helps in real-time monitoring. The result of the system validation is to evaluate the performance of active type solar tracking system; experiments conducted throughout the day from morning 8 am to evening 5 pm per 30 minutes interval from date $24^{\text {th }}$ November until $1^{\text {st }}$ December 2018. Readings from the static solar panel and automatic adaptive panel were recorded to compare on data collection. The analysis was performed to measure the energy generated by this prototype over a static panel.

Figures 10 and 11 present the reasonable data collection in average for 3 days for static solar and tracking solar panel for specific hours during daytime and performance analysis comparison between static and tracking panel. The effectiveness of the tracking system has been proved. Power generated and efficiency from the solar panel gives a higher output than a static panel. It also shows that the solar voltage suddenly falls between 5:00 to 6:00 pm after the solar tracking system is closed during the late evening. It shows that the solar tracking system operates properly to capture the higher voltage during the specific hours.

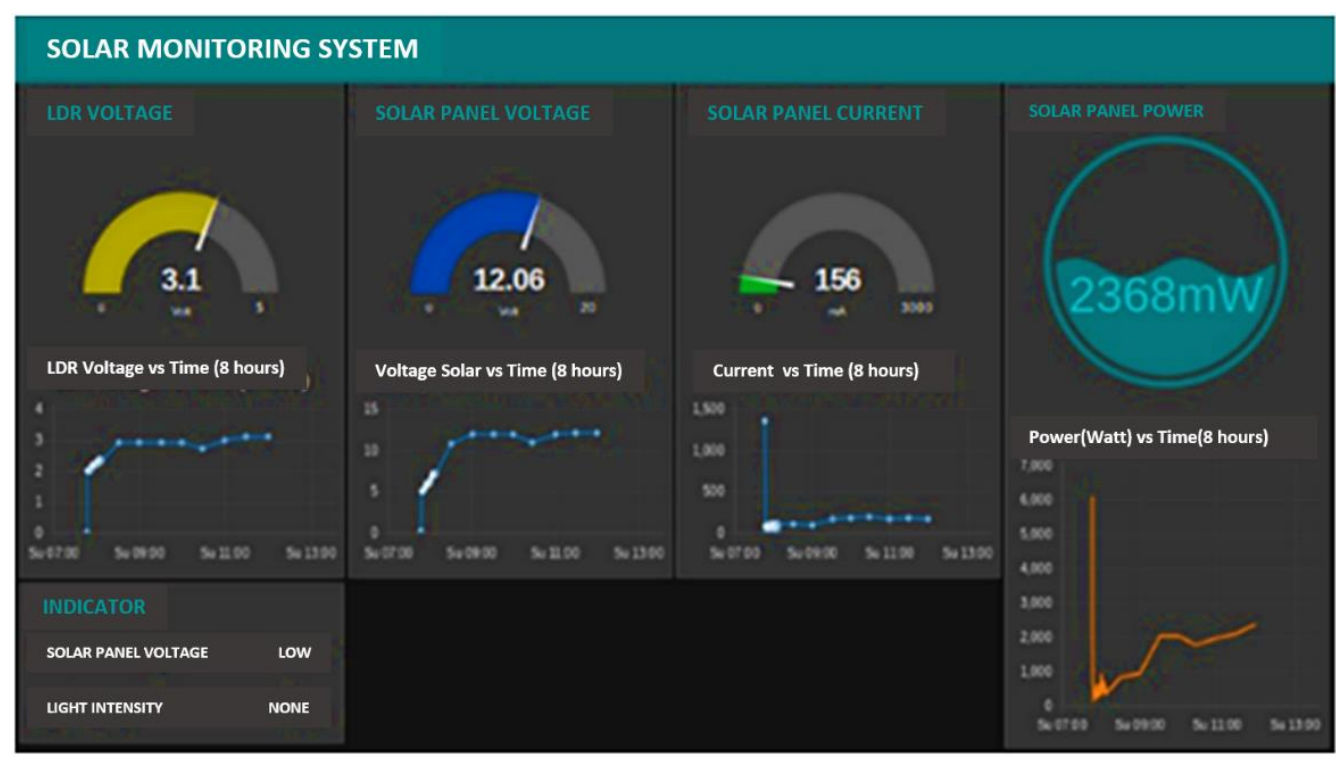

Figure 8 . Website of the system displayed 


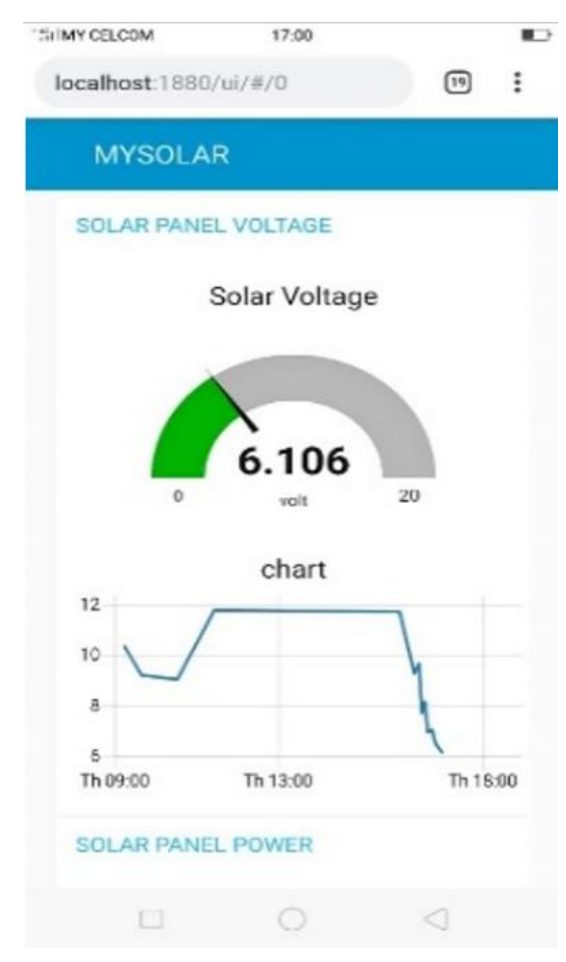

Figure 9. Android mobile displayed

Table 4 shows the overall average efficiency during data collected average for 3 days for static solar panel and tracking solar panel for specific hours from date 24th November until 1st December 2018 during the daytime. The most efficient solar panel operates is $19.13 \%$ comes from 12.30 noon by the tracking panel. The prototype initiates that the tracking excels over the static panel when the voltage, $\mathrm{V}_{\mathrm{oc}}$ is below $11 \mathrm{~V}$. As a result, the overall efficiency comparison was successful, and the tracking panel achieved total efficiency increase by about $51.82 \%$ compared to the static panel.

\section{Comparison between Average Voltage Static Solar Panel and Tracking Solar Panel wrt Time}

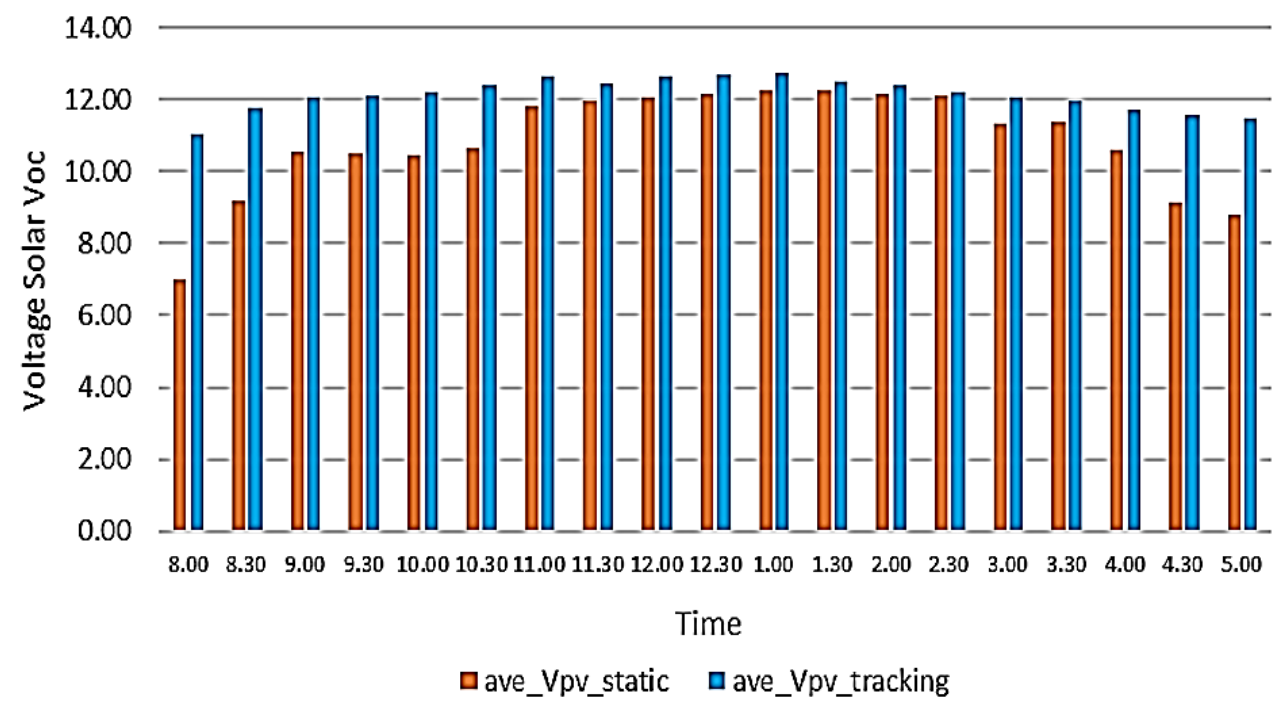

Figure 10. Average voltage readings (Volts) for static solar panel and automatic adaptive solar PV module 


\section{Comparison between Average Power generated Static Solar Panel and tracking Solar Panel wrt Time}

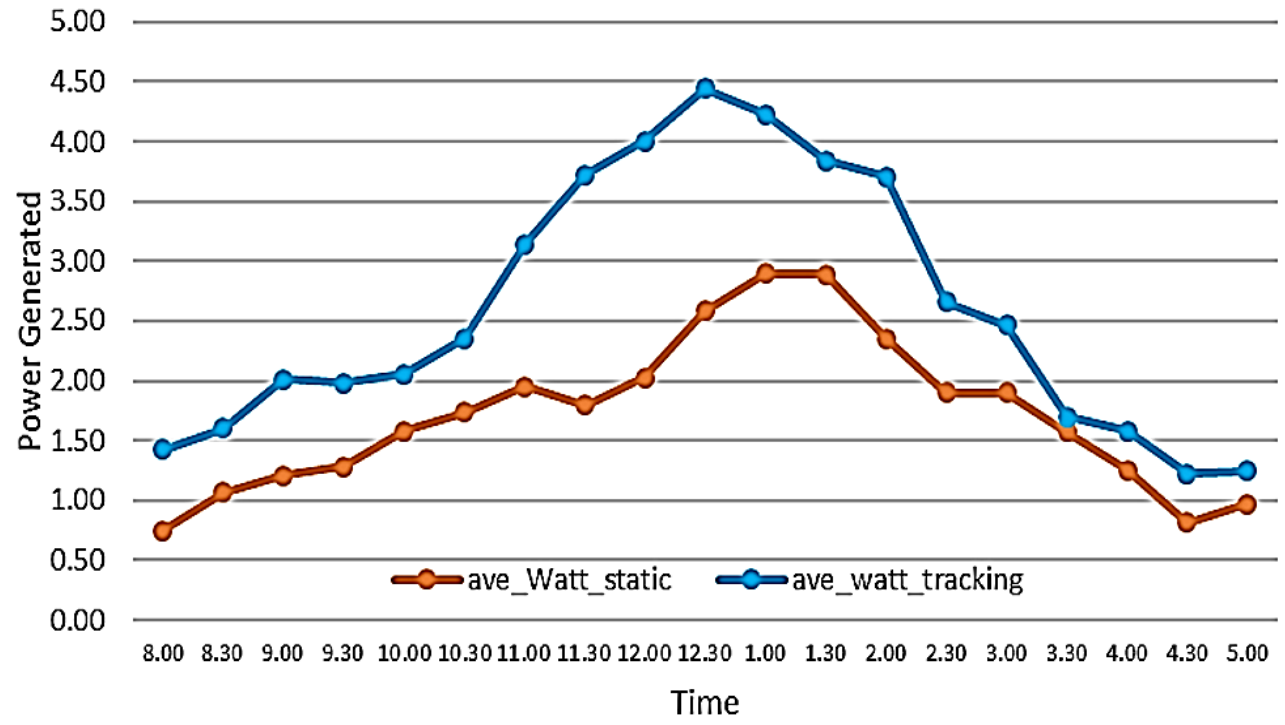

Figure 11. Average power readings (Watt) for static solar panel in 3days and automatic adaptive solar PV module

Table 4. The average total efficiency of static solar panel and tracking solar panel

\begin{tabular}{ccccc}
\hline Time (hours) & Power PV_static (Watt) & Efficiency PV_static (\%) & Power PV_track (Watt) & Efficiency PV_track (\%) \\
\hline $8: 00$ & 0.75 & 3.24 & 1.42 & 6.19 \\
$8: 30$ & 1.07 & 4.64 & 1.61 & 6.98 \\
$9: 00$ & 1.21 & 5.25 & 2.01 & 8.76 \\
$9: 30$ & 1.29 & 5.59 & 1.98 & 8.63 \\
$10: 00$ & 1.58 & 6.87 & 2.05 & 10.93 \\
$10: 30$ & 1.74 & 7.56 & 2.36 & 13.66 \\
$11: 00$ & 1.95 & 8.48 & 3.14 & 16.19 \\
$11: 30$ & 1.80 & 7.81 & 3.72 & 17.41 \\
$12: 00$ & 2.03 & 8.80 & 4.00 & 19.30 \\
12.30 & 2.58 & 11.24 & 4.44 & 18.37 \\
$13: 00$ & 2.89 & 12.58 & 4.23 & 16.70 \\
$13: 30$ & 2.89 & 12.56 & 3.84 & 16.12 \\
$14: 00$ & 2.35 & 10.23 & 3.71 & 11.56 \\
$14: 30$ & 1.90 & 8.27 & 2.66 & 10.73 \\
$15: 00$ & 1.90 & 8.27 & 2.47 & 7.41 \\
$15: 30$ & 1.58 & 6.85 & 1.70 & 6.86 \\
$16: 00$ & 1.25 & 5.45 & 1.58 & 5.33 \\
$16: 30$ & 0.82 & 3.56 & 1.23 & 5.43 \\
$17: 00$ & 0.97 & 4.23 & 1.25 & AVE:11.31 \\
& \multicolumn{5}{c}{ AVE: 7.45} & & $51.82 \%$ \\
\hline
\end{tabular}

\section{CONCLUSION}

This research has successful designed a prototype of an automatic adaptive solar PV module with a monitoring system. Data analytics platform has been designed for real time parameter measured such as voltage LDR, voltage solar, current solar and power. Real time data are captured in seconds that can be accessed from a remote location. The result presents that the static solar panel provides lower energy collected from 8:00 to 11:00 am and 3:30 to 5:00 pm. This prototype was successful to maintain a solar panel at sufficient energy collected. The power gained over a static solar panel reached $51.82 \%$. Solar tracking has been proved that the easiest method to increase power and efficiency. It is advisable to use as an educator training kit embedded with a monitoring system in an interactive approach and user-friendly. Future work can be implemented for the large scale solar photovoltaic plant, long-range (LoRa) gateway can be used together with Raspberry Pi 3 as a medium communication. LoRa is one of wireless technology designed for less energy application for large scale area coverage up to $10 \mathrm{~km}$ connected to millions of devices once for one gateway. 


\section{ACKNOWLEDGEMENTS}

Authors would like to thank the Research Management Institute (RMC), Universiti Teknologi MARA for the supports grant in publishing this paper.

\section{REFERENCES}

[1] N. K. Kasim, N. M. Obaid, H. G. Abood, R. A. Mahdi, and A. M. Humada, "Experimental study for the effect of dust cleaning on the performance of grid-tied photovoltaic solar systems," International Journal of Electrical and Computer Engineering (IJECE), vol. 11, no. 1, pp. 74-83, 2021, doi: 10.11591/ijece.v11i1.pp74-83.

[2] K. H. Hassan, A. T. Rashid, and B. H. Jasim, "Parameters estimation of solar photovoltaic module using camel behavior search algorithm," International Journal of Electrical and Computer Engineering (IJECE), vol. 11, no. 1, pp. 788-793, 2021, doi: 10.11591/ijece.v11i1.pp788-793.

[3] M. Nassereddine, K. Ali, and C. Nohra, "Photovoltaic solar farm: Earthing system design for cost reduction and system compliance," International Journal of Electrical and Computer Engineering (IJECE), vol. 10, no. 3, pp. 2884-2893, 2020, doi: 10.11591/ijece.v10i3.pp2884-2893.

[4] C. Breyer et al., "Solar photovoltaics demand for the global energy transition in the power sector," Progress in Photovoltaics: Research and Applications, vol. 26, no. 8, pp. 505-523, 2017, doi: 10.1002/pip.2950.

[5] S. Yusoff and A. S. Rosli, "The implication of feed-in tariff funding structureand the sustainability of renewable energy in Malaysia," 9th International Conference on Researches in Engineering Technology and Sciences (ICRETS), 2015, pp. 1-6.

[6] M. Ghazali and S. N. Azlina, "Renewable energy in Malaysia: The viability of large scale introduction of solar PV for both Gridconnected and stand-alone hybrid systems," Thesis, University of Otago, 2013.

[7] A. Samantha, R. Varma, and S. Bhatt, "Chronological single axis solar tracker," International Journal of Engineering Trends and Technology (IJETT), vol. 21, no. 3, pp. 204-207, 2013.

[8] M. Fuentes, M. Vivar, J. Burgos, J. Aguilera, and J. Vacas, "Design of an accurate, low-cost autonomous data logger for PV system monitoring using Arduino ${ }^{\mathrm{TM}}$ that complies with IEC standards," Solar Energy Materials and Solar Cells, vol. 130, pp. 529-543, 2014, doi: 10.1016/j.solmat.2014.08.008.

[9] G. K. Singh, "Solar power generation by PV (photovoltaic) technology: A review," Energy, vol. 53, pp. 1-13, 2013, doi: $10.1016 /$ j.energy.2013.02.057.

[10] S. Patil, M. Vijayalashmi, and R. Tapaskar, "Solar energy monitoring system using IOT," Indian Journal of Scientific Research, vol. 15 , no. 2, pp. 149-155, 2017

[11] N. H. B. Hisham, M. Kassim, N. Arbain, and N. Ya'acob, "IoT gaming system with generating power energy," 2019 IEEE 9th International Conference on System Engineering and Technology (ICSET), 2019, pp. 281-286, doi: 10.1109/ICSEngT.2019.8906383.

[12] J. Gubbi, R. Buyya, S. Marusic, and M. Palaniswami, "Internet of things (IoT): A vision, architectural elements, and future directions," Future generation computer systems, vol. 29, no. 7, pp. 1645-1660, 2013, doi: 10.1016/j.future.2013.01.010.

[13] S. Sruthy and S. N. George, "WiFi enabled home security surveillance system using Raspberry Pi and IoT module," 2017 IEEE International Conference on Signal Processing, Informatics, Communication and Energy Systems (SPICES), 2017, pp. 1-6, doi: 10.1109/SPICES.2017.8091320

[14] P. Visconti, A. Lay-Ekuakille, P. Primiceri, and G. Cavalera, "Wireless energy monitoring system of photovoltaic plants with smart anti-theft solution integrated with control unit of household electrical consumption," International Journal on Smart Sensing \& Intelligent Systems, vol. 9, no. 2, pp. 681-708, 2016, doi: 10.21307/ijssis-2017-890.

[15] D. R. P. Patnaikuni, "A comparative study of arduino, Raspberry Pi and ESP8266 as IoT development board," International Journal of Advanced Research in Computer Science, vol. 8, no. 5, pp. 2350-2352, 2017, doi: 10.26483/ijarcs.v8i5.3959.

[16] F. Salamone, L. Belussi, L. Danza, M. Ghellere, and I. Meroni, "An open source low-cost wireless control system for a forced circulation solar plant," Sensors, vol. 15, no. 11, pp. 27990-28004, 2015, doi: 10.3390/s151127990.

[17] B. D. E. Mahdi, H. Abdelatif, and M. A. Zafrane, "An interactive approach for solar energy system: Design and manufacturing," International Journal of Electrical and Computer Engineering (IJECE), vol. 10, no. 5, pp. 4478-4489, 2020, doi: 10.11591/ijece.v10i5.pp4478-4489.

[18] N. Ya'Acob, N. Tajudin, A. L. Yusof, M. Kassim, S. S. Sarnin, and N. Z. Zaharudin, "Investigation of ionospheric scintillation and total electron content during maximum and minimum solar cycle," 2019 International Symposium on Networks, Computers and Communications (ISNCC), 2019, pp. 1-6, doi: 10.1109/ISNCC.2019.8909120.

[19] R. Banerjee, "Solar tracking system," International Journal of Scientific and Research Publications, vol. 5, no. 3, pp. 1-7, 2015.

[20] M. Kassim, C. K. Haroswati, C. K. Yahaya, and M. N. Ismail, "A prototype of web based temperature monitoring system," 2010 2nd International Conference on Education Technology and Computer, vol. 5, 2010, pp. V5266-V5270, doi: $10.1109 /$ icetc.2010.5530066.

[21] M. Kassim, M. A. Rahman, C. K. H. C. K. Yahya, and A. Idris, "Mobile application for electric power monitoring on energy consumptions at a campus university," Indonesian Journal of Electrical Engineering and Computer Science (IJEECS), vol. 11, no. 2, pp. 637-644, 2018, doi: 10.11591/ijeecs.v11.i2.pp637-644.

[22] K. Sadovskaia, "Comparison of efficiencies of solar tracker systems with static panel single-axis tracking system and dual-axis tracking system with fixed mount," Classical and Quantum Gravity, vol. 32, no. 7, 2015.

[23] A. S. C. Roong and S. H. Chong, "Laboratory-scale single axis solar tracking system: Design and implementation," International Journal of Power Electronics and Drive Systems (IJPEDS), vol. 7, no. 1, pp. 254-264, 2016, doi: 10.11591/ijpeds.v7.i1.pp254264.

[24] P. Arlikar, A. Bhowmik, M. Patil, and A. Deshpande, "Three dimensional solar tracker with unique sensor arrangement," 2015 International Conference on Smart Technologies and Management for Computing, Communication, Controls, Energy and Materials (ICSTM), 2015, pp. 509-513, doi: 10.1109/icstm.2015.7225470.

[25] C. Lawless and E. Kärrfelt, "Sun following solar panel: Using light sensors to implementsolar tracking," Thesis, the Royal Institute Of Technology School Of Industrial Engineering And Management TRITA-ITM-EX, 2018.

[26] N. Barsoum, "Fabrication of dual-axis solar tracking controller project," Intelligent Control and Automation, vol. 2, no. 02, pp. 57-68, 2011, doi: 10.4236/ica.2011.22007.

[27] H. Allamehzadeh, "Solar energy overview and maximizing power output of a solar array using sun trackers," 2016 IEEE Conference on Technologies for Sustainability (SusTech), 2016, pp. 14-19, doi: 10.1109/SusTech.2016.7897136. 
[28] K. Pranesh and K. Saranya, "Solar tracking system using DC gear motor," Journal on Appications of Information and Communication Engineering, vol. 1, no. 2, pp. 20-23, 2015.

[29] S. Dasgupta, F. W. Suwandi, S. Sahoo, and S. Panda, "Dual axis sun tracking system with PV cell as the sensor, utilizing hybrid electrical characteristics of the cell to determine insolation," 2010 IEEE International Conference on Sustainable Energy Technologies (ICSET), 2010, pp. 1-5, doi: 10.1109/ICSET.2010.5684424.

[30] P. Arjyadhara, S. Ali, and J. Chitralekha, "Analysis of solar PV cell performance with changing irradiance and temperature," International Journal of Engineering and Computer Science, vol. 2, no. 01, pp. 214-220, 2013.

\section{BIOGRAPHIES OF AUTHORS}

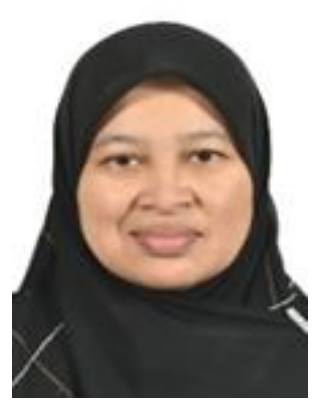

Murizah Kassim (D) 81 SC P is currently working as Associate Professor at School of Electrical Engineering, College of Engineering, Universiti Teknologi MARA, Shah Alam, Selangor. She received her PhD in Electronic, Electrical and System Engineering in 2016 from the Faculty of Built Environment and Engineering, Universiti Kebangsaan Malaysia (UKM). She has published many indexed papers related to computer network, IoT, Web and Mobile development applications research. She experienced for 19 years in the technical team at the Centre for Integrated Information System, UiTM. She is also head of enabling internet of things technologies (ElIoTT) research group UiTM. She joined the academic since January 2009 and currently member of MBOT, IEEE, IET, IAENG and IACSIT organization. She can be contacted at email: murizah@uitm.edu.my.

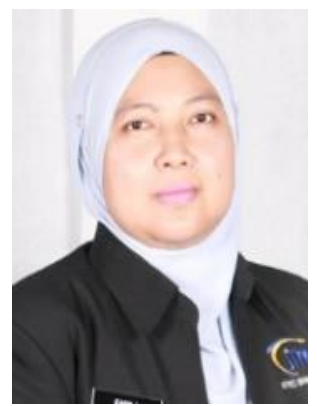

Fadila Lazim (D) 8D SC P is currently working with Pusat Latihan Teknologi Tinggi (ADTEC) in Shah Alam. She received her master's degree in Telecommunication and Information Engineering, from Universiti Teknologi MARA (UiTM), Shah Alam, Selangor Malaysia under Faculty of Electrical Engineering in 2018. Currently, she is leading the electrical power division at ADTEC. She can be contacted at email: fadilalazim@gmail.com. 